7. Cui H, Schaff HV, Geske JB, Lahr BD, Dearani JA, Nishimura RA, et al. Early septal reduction therapy for patients with obstructive hypertrophic cardiomyopathy. J Thorac Cardiovasc Surg. 2022;164:1502-9.e5.

8. Cavigli L, Fumagalli C, Maurizi N, Rossi A, Arretini A, Targetti M, et al. Timing of invasive septal reduction therapies and outcome of patients with obstructive hypertrophic cardiomyopathy. Int J Cardiol. 2018; 273:155-61.
9. Maron BJ, Dearani JA, Ommen SR, Maron MS, Schaff HV, Nishimura RA, et al. Low operative mortality achieved with surgical septal myectomy: role of dedicated hypertrophic cardiomyopathy centers in the management of dynamic subaortic obstruction. J Am Coll Cardiol. 2015;66:1307-8.

10. Mazine A, Ghoneim A, Bouhout I, Fortin W, Berania I, L'Allier PL, et al. A novel minimally invasive approach for surgical septal myectomy. Can J Cardiol. 2016; $32: 1340-7$.
See Article page 1502.

\section{Commentary: Septal reduction therapy: The sooner, the better?}

\author{
Lawrence M. Wei, MD
}

What is the impact of early septal reduction therapy (SRT) on patients with obstructive hypertrophic cardiomyopathy (HCM)? In this issue of the Journal, Cui and colleagues ${ }^{1}$ present a study of 1351 patients with obstructive HCM evaluated at the Mayo Clinic from 2000 to 2012. Early SRT, defined as septal myectomy (SM) or alcohol septal ablation (ASA) within 6 months of index evaluation, was performed in 884 patients $(65.4 \%)$, whereas 467 patients $(34.6 \%)$ were initially treated medically. Follow-up starting at the 6-month landmark point as "time zero" continued for 15 years (median, 10 years), with mortality the primary endpoint.

The most striking finding, clearly illustrated in the article's central picture, is that early SRT provides a survival benefit compared with medical treatment. This difference was even more pronounced after the patients were riskadjusted for age and comorbidities. There was heterogeneity of treatment effect, with increased benefit of early SRT in women, patients in New York Heart Association class IIIIV, and nondiabetics.

\footnotetext{
From the Department of Cardiovascular and Thoracic Surgery, West Virginia University, Morgantown, WVa.

Disclosures: The author reported no conflicts of interest.

The Journal policy requires editors and reviewers to disclose conflicts of interest and to decline handling or reviewing manuscripts for which they may have a conflict of interest. The editors and reviewers of this article have no conflicts of interest.

Received for publication Nov 8, 2020; revisions received Nov 8, 2020; accepted for publication Nov 11, 2020; available ahead of print Nov 20, 2020.

Address for reprints: Lawrence M. Wei, MD, Department of Cardiovascular and Thoracic Surgery, West Virginia University Heart and Vascular Institute, PO Box 8003, One Medical Center Drive, Morgantown, WV 26506 (E-mail: lawrence. wei@wvumedicine.org).

J Thorac Cardiovasc Surg 2022;164:1513-4

$0022-5223 / \$ 36.00$

Copyright (C) 2020 by The American Association for Thoracic Surgery

https://doi.org/10.1016/j.jtcvs.2020.11.035
}

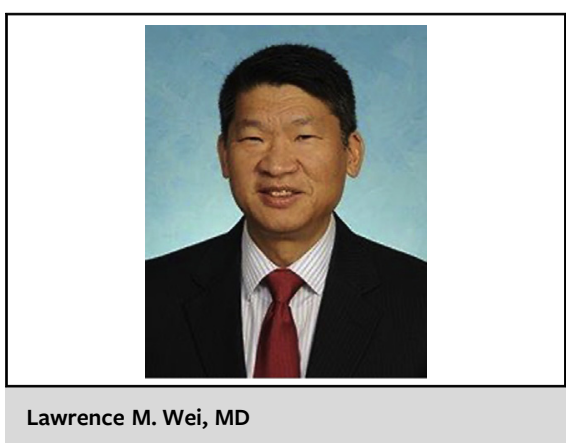

CENTRAL MESSAGE

Early septal reduction therapy

(SRT) may provide a survival

benefit over medical

management.

There are some limitations to the study, in that it is a retrospective, nonrandomized study at a tertiary referral center that performs SRT with excellent outcomes and thus might not be applicable to all institutions. It is important to note that "early" refers to the course of management and not to the disease stage. Patients with HCM may be diagnosed at various points in the disease process, some by screening and others by clinical presentation. They may be referred at varied points after diagnosis, making time from referral rather than time from diagnosis an appropriate basis for the study's design. The patients in this study are highly selected, having been referred to a tertiary care center for treatment, and the results of this study cannot be generalized to all patients diagnosed with obstructive HCM.

Septal myectomy is safe and effectively eliminates outflow tract obstruction in HCM, providing excellent relief of heart failure symptoms. ${ }^{2}$ Alcohol septal ablation is a viable alternative to SM for many patients, especially those at high surgical risk. ${ }^{3}$ However, current guidelines, based on 
data from an earlier era when the risk of invasive therapy was higher, support medical management as primary therapy and recommend reserving SRT for patients refractory to medical therapy. ${ }^{4}$ Some experts have suggested that given the low procedural risk at experienced centers and predictable relief of symptoms with surgery that septal myectomy should be considered earlier in the management of obstructive HCM. ${ }^{5}$ This study suggests that a strategy of earlier intervention not only may provide better symptom relief, but also may improve long-term survival. Although this is not a randomized prospective study, which would not be feasible in this patient population, it is well designed and executed, with good statistical support for its conclusions. If the results are confirmed at other institutions, it could lead to a shift in the paradigm for management of obstructive HCM toward a strategy of earlier intervention.

\section{References}

1. Cui H, Schaff HV, Geske JB, Lahr BD, Dearani JA, Nishimura RA, et al. Early septal reduction therapy for patients with obstructive hypertrophic cardiomyopathy. J Thorac Cardiovasc Surg. 2022;164:1502-9.e5.

2. Maron BJ, Dearani JA, Ommen SR, Maron MS, Schaff HV, Nishimura RA, et al Low operative mortality achieved with surgical septal myectomy: role of dedicated hypertrophic cardiomyopathy centers in the management of dynamic sub aortic obstruction. J Am Coll Cardiol. 2015;66:1307-8.

3. Batzner A, Pfeiffer B, Neugeberger A, Aicha D, Blank C, Seggewiss H. Survival after alcohol septal ablation in patients with hypertrophic obstructive cardiomyopathy. J Am Coll Cardiol. 2018;72:3087-94.

4. American College of Cardiology Foundation/American Heart Association Task Force on Practice, American Association for Thoracic Surgery, American Society of Echocardiography, American Society of Nuclear Cardiology, Heart Failure Society of America, Heart Rhythm Society, et al. 2011 ACCF/AHA guideline for the diagnosis and treatment of hypertrophic cardiomyopathy: a report of the American College of Cardiology Foundation/American Heart Association task force on practice guidelines. J Thorac Cardiovasc Surg. 2011; 142:e153-203.

5. Maron MS, Spirito P, Maron BJ. Case for earlier surgical myectomy in patients with obstructive hypertrophic cardiomyopathy. Circulation. 2018;138:2076-8. 